\section{Opinion study on Vasectomy, Sterilized Version of Male Contraception}

\section{Abstract}

Vasectomy, it is well known heard around the world as the extreme perfect sterilized process of contraception which is known to be synonym of contraception for males, male animals too. Amid vasectomy, a medicinal services supplier closes or obstructs the tubes that convey sperm. At the point when the tubes are shut, sperm can't leave a man's body and cause pregnancy. Sperms are made in the Gonads will go through two tubes called the vasa differentia to different organs and blend with original liquids to frame semen. Vasectomy obstructs every vas deferens and keeps sperm out of the original liquid. Sperms are consumed by the body as opposed to being discharged. Without your thickened sperm (discharge) can't bring the suspect chance on pregnancy.

Keywords: Vasectomy; Contraception; Sperm; Gonads

\section{Audrey Kanes}

Department of Endocrinology, Universidad de São Paulo, Brazil

\section{Corresponding author: Audrey Kanes}

झ audreykanes@rediffmail.com

Professor, Department of Endocrinology, Universidad de São Paulo, Brazil.

Tel: +55 $193521-7000$

Citation: Kanes A. Opinion study on Vasectomy, Sterilized Version of Male Contraception. J Contracept Stud. 2017, 2:1

Received: March 02, 2017, Accepted: March 09, 2017 Published: March 16, 2017

\section{Sterilized Procedure}

There are diverse routes for men to be cleaned. One write does not require an entry point - a cut. Alternate sorts of vasectomy require an entry point. Cut strategies take around $20 \mathrm{~min}$ [1-3]. The no-entry point strategy takes less time. Method of Incision and Non-advanced methods are now popular to the sterilized version of vasectomy and they are quite safe too. Let us know about them as in Intro type In general, a nearby analgesic is infused into the pelvic zone. At that point, the specialist makes an entry point on each side of the scrotum to achieve every vas deferens -the tubes that convey sperm. Here and there a solitary entry point is made in the middle. Each tube is blocked. In many methods, a little area of each tube is evacuated [4,5]. Tubes might be tied off or obstructed with surgical clasps. Or, on the other hand, they might be shut utilizing an instrument with an electrical current. Non-septic, it means non incised method, with the no-entry point ("no-surgical blade") technique, the skin of the scrotum is not cut. One small cut is made to achieve both tubes. The tubes are then tied off, closed up, or blocked (Figures 1 and 2). The modest cut mends rapidly. No lines are required, and no scarring happens. The no-surgical tool strategy lessens draining and diminishes the likelihood of contamination, wounding, and different complexities [6-9].

\section{Positive Aspects of Vasectomy}

Vasectomy is protected and, on the grounds that it goes
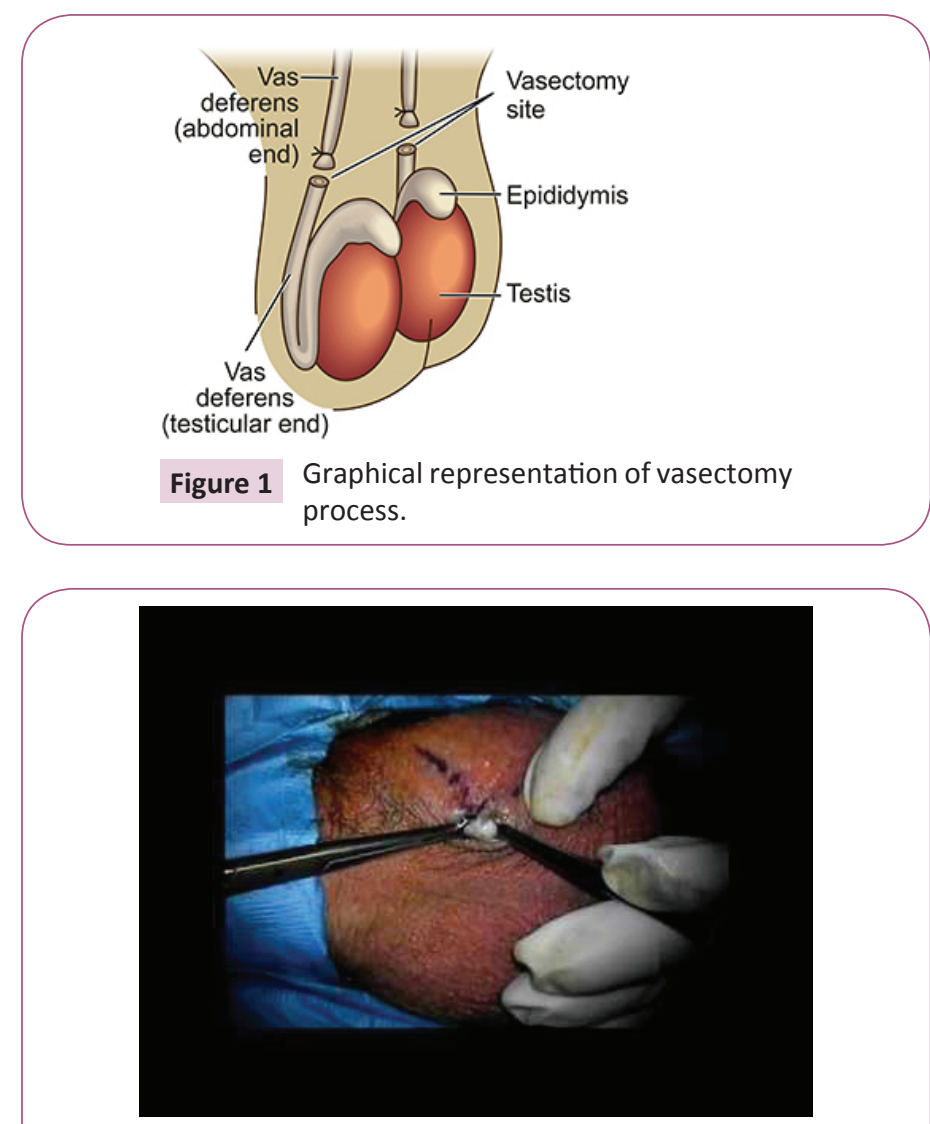

Figure 2 Vasectomy and sealing of outer skin layer. 
on forever, it is basic and helpful. It permits ladies and men to appreciate sex without stressing over pregnancy $[10,11]$. Vasectomy does not change your hormones or manliness. What's more, it won't influence your capacity to get and remain erect. It likewise won't influence your sex organs, sexuality, and sexual joy $[12,13]$. No organs or organs are expelled or modified. Your hormones and

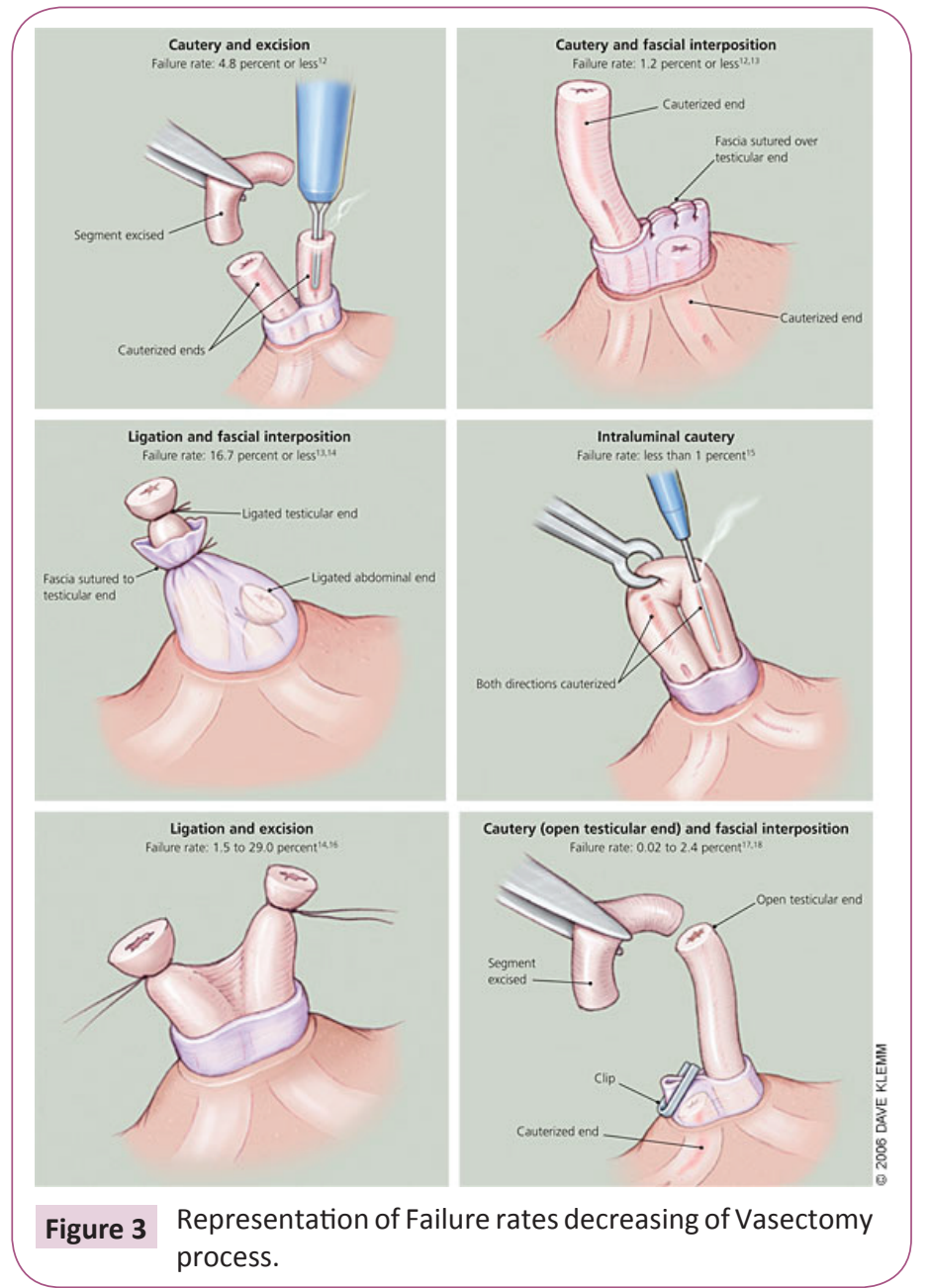

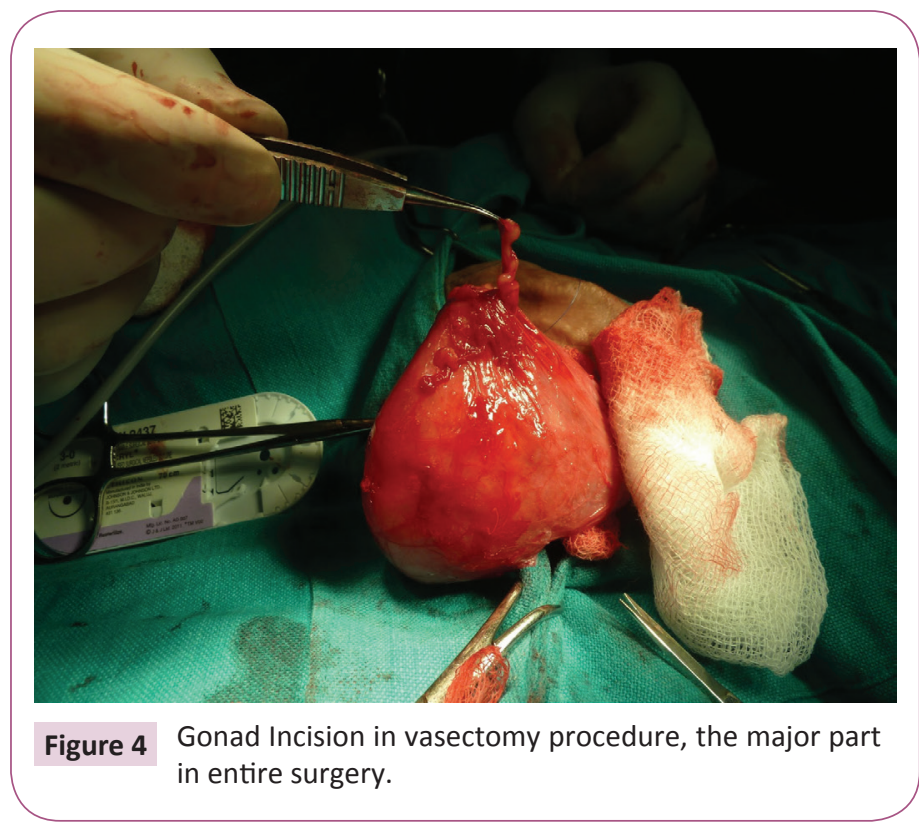

sperm keep being created. Your discharge will look simply like it generally did. What's more, there will be about an indistinguishable sum from some time recently (Figures 3 and 4 ).

\section{Conclusion}

Vasectomy is the best perpetual type of contraception accessible to men. In almost every way that vasectomy can be contrasted with tubal ligation it has a more inspirational standpoint. Vasectomy is more financially savvy, less obtrusive, has procedures that are rising that may encourage simpler inversion, and has a much lower danger of postoperative complexities [14,15]. In spite of this, in the United States, vasectomy is used at not as much as a large portion of the rate of the option female "tubal ligation". According to the exploration, vasectomy is minimum used among dark and Latin populaces, the US bunches that have the most noteworthy rates of female cleansing. 


\section{References}

1 Hatcher RA, Trussell J, Stewart F, Stewart GK, Kowal D, et al. (1994) Voluntary surgical contraception. Contraceptive technology. Manchester (NH): Irvington, 379-414.

2 Schlegel PN, Goldstein M. Shoupe D, Haseltine FP (1993) Vasectomy In: Contraception. New York: Springer-Verlag, pp: 181-191.

3 Liskin I, Renoir E, Blackburn R (1992) Vasectomy-new opportunities. Population Reports 5: 1-23.

4 Liu X, Li S (1993) Vasal sterilization in China. Contraception, 48: 255-66.

5 Piccinino LJ, Mosher WD (1998) Trends in contraceptive use in the United States. Fam Plann Perspect 30: 4-10.

6 Forste R, Tanfer K, Tedrow L (1995) Sterilization among currently married men in the United States. Fam Plann Perspect 27: 100-107.

7 Massey FJ, Bernstein GS, O'Fallon WM, Schuman LM, Coulson AH, et al. (1984) Vasectomy and health-results from a large cohort study. JAMA 252: 1023-1029.

8 Perlman JA, Spiritas R, Kelaghan J, Madans J, Cox C, et al. (1991)
Vasectomy and the risk of prostate cancer. Am J Epidemiol 134: 107108.

9 Marquette CM, Koonin LM, Antarsh L, Gargiullo PM, Smith JC, et al. (1991) Vasectomy in the US, Am J Public Health, 85: 644-649.

10 Goldstein M (1992) Campbell's urology (6th ed.), Philadelphia: WB Saunders, 3114-3149.

11 Davis LE, Stockton MD (1997) No-scalpel vasectomy. Primary Care, 24: 433-461.

12 Li S, Goldstein M, Huber D (1991) The no-scalpel vasectomy. J Urol, 115: 341-344.

13 Babayan RK, Krane RJ (1986) Vasectomy: what are community standards? Urology 27: 328-330.

14 International Planned Parenthood Federation (1999) London: International Medical Advisory Panel (IMAP) Statement on Voluntary Surgical Sterilisation.

15 Peterson HB, Xia Z, Hughes JM, Wilcox LS, Tylor LR, et al. (1996) The risk of pregnancy after tubal sterilization: findings from the U.S. Collaborative Review of Sterilization. Am J Obstet Gynecol 174: 1161-1168. 